\title{
The Integration of Moral Education and Efficient Classroom in Secondary Vocational School
}

\author{
Wang Weizhi \\ Qingdao Huanghai University \\ P.R.China \\ 1638823661@qq.com
}

\author{
Xu Yuanyuan \\ Qingdao Huanghai University \\ P.R.China \\ 2678780687@qq.com \\ Ding Lingling \\ Qingdao Huanghai University \\ P.R.China \\ 153653901@qq.com
}

\begin{abstract}
Moral education is the cornerstone of teaching and education in schools, and the success of education has a direct impact on students' work as a human being. Moral education in secondary vocational schools is more specific. This article focuses on how moral education integrates with efficient classroom, analyzes the defects of general classroom teaching of moral education, expounds the significance of combining efficient classroom with moral education in secondary vocational schools, probes into the innovation of moral education in efficient classroom, solves the problem of separation between moral education and professional education, and points out the basic way of moral education in the efficient classroom teaching.
\end{abstract}

Keywords-moral education; efficient classroom; education; integration

\section{INTRODUCTION}

Moral education plays an important role in the education of secondary vocational school. "Outline of China's Educational Reform and Development" pointed out that the educators need to put moral education throughout the whole process of education and teaching, pay attention to moral education, Integrate moral education into every aspect of students' study and life, which has a great influence on the growth of students. In order to continuously strengthen and improve the moral education work and achieve the important effect of school moral education, educators have paid a lot of effort, and through a series of efforts, they have achieved important results With the development of social politics and economy, the moral education in secondary vocational colleges is facing a new and major challenge. Only by renewing the mode and means of moral education constantly can we promote the innovation of moral education in secondary vocational schools.

\section{ANALYSIS OF EFFICIENT EDUCATION IN TRADITIONAL TEACHING}

\section{A. Teachers don't pay enough attention to moral education.}

Some teachers do not have the initiative to carry out moral education in the course of completing the teaching task, and they do not realize the importance of moral education. Often, most of them think that their classroom responsibilities are just to teach specialized courses and do not carry out moral education at the same time. What is more, they think moral education is only the duty and task of the ideological and political teachers and counselor, not the teachers'. Thomas Likona, a contemporary American moral education expert, once pointed out that, the education of various subjects is a "sleeping dragon" for moral education, with great potential"[1]. The key point of the moral education is the traditional moral education, so the moral education in the classroom teaching is the key breakthrough point of the moral education work. As educators, we should innovate actively on the current teaching practice, and strive to seize the connection of classroom teaching and moral education, and put moral education into practical teaching in professional course.

\section{B. Teachers' moral education consciousness is out of balance}

Only with a strong sense of moral education, teachers in the teaching process will combine the knowledge of moral education, pay attention to the ideological and moral situation of students. The teachers with no moral consciousness will not pay enough attention to the moral education, and usually will ignore the prerequisite for the explicit requirements of the syllabus. Different educators have great differences in the development and effectiveness of the subject moral education in the actual teaching process. Generally, emphasis on putting moral education into practice and research of subject teaching is pretty random, which is different from knowledge teaching.

\section{General teaching lacks the guarantee mechanism of moral education}

The evaluation of teaching effectiveness in the traditional classroom usually is based on the mastery of theoretical knowledge. For example, for teachers' performance appraisal and professional title evaluation, our standards are only professional and academic, which can be quantified by hard indicators. But in the aspect of moral education, there is no principle requirements of actual standards, or only 
pro formal requirement, and sometimes there is even no requirement [2].

\section{THE INTRODUCTION OF EFFICIENT CLASSROOM}

Moral education needs carrier. Doing moral education in the form of moral education will get half the results with double the effort. Moral education needs to be closely integrated with classroom teaching. Moral education is salt, but only with food is delicious, and efficient classroom is this "delicious food".

In order to solve the above shortcomings, we have introduced efficient classroom teaching. Brief explanation of efficient classroom: Efficient classroom is based on "human oriented"[3]. It is the classroom to train students' learning ability, basic quality, innovative spirit, will and character, social responsibility and practical ability. Its can be vividly described as "knowledge supermarket", "Life Carnival"". It has three main features: initiative, vivid and generative. But efficient classroom is not a simple teaching concept. It is a new educational concept constructed from three major systems: teaching, evaluation and culture. It should be expressed as efficient classroom education.

Significant breakthrough in efficient classroom: changing ideas and promoting upgrading. Change the centers from "teachers" to "students", from "knowledge" to "ability", from "simple examination" to "comprehensive quality", from teacher-student interaction to student-student interaction, from "teachers ask and students answer" to "answer each other's questions". In the process of transformation, teachers inspire students to carry out moral education, encourage students to explore moral knowledge actively, and enhance the comprehensive quality of students in real sense.

\section{THE SIGNIFICANCE OF COMBINING EFFICIENT AND MORAL EDUCATION IN SECONDARY VOCATIONAL SCHOOL}

The father of Education -- Herbart once said: "If there is no moral education, teaching is only a means without purpose; if there is no classroom teaching, moral education is a purpose of losing the means." which fully demonstrates that the integration of moral education and efficient classroom is of great practical significance.

A. The moral education of efficient classroom is in line with
the current situation of secondary vocational education

At present, students in secondary vocational school are generally characterized by their weak learning ability and strong practical ability. Under the premise of giving full consideration to the students' learning situation, the introduction of efficient classroom is in line with the current situation of secondary vocational education. China Education Law stipulates: "Education must serve the construction of socialist modernization, be integrated with productive labor, and train builders and successors to the cause of socialism who are well developed morally, intellectually and physically." The latest educational policy drawn up in the 18th CPC National Congress is that education must serve for socialist modernization construction, serve for the people, take people cultivation as the basic task, implement quality education in an all-round way, train socialist builders and successors with an all-round development, make efforts to build satisfying education. We should train comprehensive talents with all-round development of morality, intelligence and body, take moral education as the first step, as the basis for carrying out education. Efficient classroom is the effective carrier of all-round implementation of quality education. In the classroom teaching process, team cooperation and team consciousness of moral education for students is of great advantage. Team members and leaders as the subject of practice in the teacher's guidance, give full play to personal charisma, and agglomerate team cohesion, which is an important process to highlight the moral education.

\section{B. Efficient classroom is the key channel of moral education}

We can clearly realize that students' learning time in school occupies most of the school life, and how to make good use of efficient classroom plays a key role in students' moral education. Efficient classroom has its own unique advantages and characteristics. In the efficient classroom teaching, moral education should be accompanied by the whole process of teaching, and under the guidance and training of teachers, it can ensure its effective operation. At present, the efficient classroom is the most widespread education activity in all disciplines of our school, and it is the most basic and fundamental teaching link in the school education. Students acquire knowledge, enhance their own, and improve their moral qualities through efficient classroom. Through the efficient classroom, different groups display different time, different regions, different countries, different people, different material and spiritual civilization. The moral education in efficient classroom teaching, develops from the exploration of the students themselves, combined with the instruction of the teachers to the students, and has a special significance and role in the improvement of the students' ideological level. Emphasis on moral education of efficient classroom, and give full play to the important impact of efficient classroom.

\section{To better solve the separation of moral education and professional education}

In the traditional classroom, the teacher believes that the moral education is not related to the teaching process, but the efficient classroom pays more attention to the combination of moral education and subjects [4]. Because the efficient classroom teaching method is to give full play to the role of group learning, the group's study and exploration is carried out under the leadership of the group leader. If the team leader does not have enough moral and charisma, it is difficult to lead his team. While the classroom teacher is in the process of carrying out the classroom, the most critical content is to guide the group team learning. In the team learning process, teachers must ask the team members to improve their overall level of moral education to achieve better team cooperation. Therefore, the efficient classroom has actively solved the problem that teachers of various disciplines pay more attention to the students' moral education, thus helping the ideological and political workers and class teachers greatly improve the overall efficiency and effectiveness of moral education. 


\section{THE BASIC WAY TO CARRY OUT MORAL EDUCATION IN EFFICIENT CLASSROOM TEACHING IN SECONDARY VOCATIONAL SCHOOLS}

The teacher is only learning guide in efficient classroom. The "guide" is not only to guide their mastery of the textbook, but also to guide students to actually play their own advantages to learn from each other, in order to achieve the best learning effect. The process of guiding students to learn from each other is in itself a process of improving moral education.

To carry out moral education mainly from the following aspects:

\section{A. Establish and improve the organization for providing moral Education for efficient classes}

Moral education in the classroom must be supported by the school administration, if there is no hard and fast standard, the teachers are not motivated to carry it out in the course of the class [5]. The teaching requirements of the school also provide the driving force for the teachers' moral education. In this way, moral education can be fully integrated with our classroom instruction, which is often not enough. At the same time, it also needs to integrate the school running idea, professional education and basic education, so as to provide sufficient guarantee for the students' moral education.

\section{B. Carrying out moral education in combination with majors}

To give full play to the unique advantages of moral education and efficient classroom integration in the subject teaching and to infiltrate moral education into classroom teaching is an important way to implement the basic purpose of "imparting knowledge and educating people". In the teaching of professional courses, the vivid teaching cases containing traditional culture and national spirit should be integrated into efficient classes. As in group presentations of students majoring in architecture, combining ancient architectural culture heritage such as Dujiang Weir and the Zhaozhou Bridge, after thousands of years can still be for the benefit of future generations, teachers should encourage students to appreciate the charm and eternity of architecture, to reflect the wisdom of the Chinese nation, to enhance the sense of national pride, and improve interest in professional learning. Another example is for the logistics majors, in group presentation of the concept of "understanding logistics time", the teacher can combine the story of Tian Ji's horse race to explain the text. Students will understand the need to use a comprehensive way of thinking about things, when the overall effect and partial interests conflict, we should pay attention to the overall effect. When necessary, we should give up partial interest to assure the overall interests. Combining Wooden Ox and Gliding Horse with mechanical design course, combining abacus with computer courses, the spread of such kind of combination of ancient and modern, promotion methods to practice, the past serving the present, creatively study and apply in the efficient classroom, not only stimulates the students' interest in learning, but also permeates the moral education, which can achieves the moral effect of "moistening things silently".

\section{Integration of aesthetic education and moral education}

Aesthetic education of secondary vocational school has a very important role in cultivating sentiments, intellectual development, physical and mental health and personality optimization. The combination of aesthetic education and moral education is an important characteristic of modern quality education and modern perfect personality education. It is also the focus of education throughout secondary vocational schools. We have made a bold attempt to explore aesthetic education of efficient classroom teaching of, such as music lesson of pre-school professional "Chinese popular music -chrysanthemum terrace". The class is started with a mildly contagious Cello, which the students all at once produce the pursuit of the beauty of music, then ask students to recite the lyrics to the music, introduce the meaning of lyrics word for word. Starting from the students' demand for music and literature appreciation, integrate the music quality, literature accomplishment, inspirational elements and patriotic feelings as one, through the group display, independent innovation, cooperation, confrontation and other exciting links, to create a vivid music features, efficient classroom.

\section{Pay attention to methods and occasions to carry out moral education}

The development of efficient classroom should focus on the integration of students' moral education into classroom development and study after class.

For example, when the students apply the guided learning case to preview, the independent learning stage must be completed by themselves, which is the cultivation of learning quality and the embodiment of the students' moral education. While displaying, teachers should encourage students to actively share their preview results. Especially the outstanding students in the group, should share their learning results without reservation, which is the cultivation of students' moral education.

\section{E. Teacher's role model}

In class teaching, teachers not only use their own professional knowledge to educate students. At the same time, teachers' words and deeds are also an example for students to learn. Teenagers have a strong ability to imitate, and their outlook on life and values are in the initial stage of formation and training [6]. Their worship and imitation of teachers determines that the teachers' words and deeds and have a great impact on them. A student will believe in teachings only when he gets close to his teacher. First of all, teachers of effective classroom should pay attention to correct their own words and deeds, not to mislead the students, not to bring bad atmosphere in society to the classroom, and influence the students personality cultivation and formation; Secondly, teachers of efficient classroom should pay attention to improve their ideological and moral realm, which can play a key role in students' development; Thirdly, teachers of efficient classroom should enhance their basic teaching skills, and macro-control the classroom, to ensure that students' show class can be carried out smoothly under the guidance of the teachers. 


\section{SUMMARY}

School is the cradle of cultivating students and the tower of ivory for everyone to aspire to. Moral education has a long way to go. While carrying out effective class, teachers should pay attention to moral education. Combined with the penetration of their own guiding case, the display and review of the class, teachers should cultivate students' correct world outlook, outlook on life and values so as to train students with all-round development of morality, intelligence, body and beauty, so as to reach the highest level of education.

\section{ACKNOWLEDGMENT}

This work was financially supported by the Teaching Reform Research Projects of Vocational Education in Shandong Province (NO: 2015672).

\section{REFERENCES}

[1] Ding Laiming, Cui Qisheng. Efficient Classroom Evaluation. Changsha: Hunan people's publishing house, 2014(18).

[2] Tong Zhaoji, Qiao Juan. The Implementation of the Effective Classroom of Vocational Schools in [J]. Road to Success, 2012 (22).

[3] Chang Guangping, Yan Lihua. Practical Exploration of Vocational Ability Evaluation of Secondary Vocational Students [J]. China Vocational and technical education, 2013 (35).

[4] Wang Qian, Construction and Exploration of Efficient Classroom in Secondary Vocational Education, Management, Science and Technology of Small and Medium Enterprises, 2016-03.

[5] Li Mengqing, $\mathrm{Xu}$ Yanping. Management and Countermeasures of Mental Health Problems in Secondary Vocational School Students [J]. Vocational and Technical Education, 2012 (4).

[6] Chen Li, secondary vocational school students' study habits and the construction of efficient classroom, Popular Science (Science Education), 2016-9. 